\title{
PLATELET RICH FIBRIN (PRF) IN PERIODONTAL REGENERATION
}

\author{
Jananni.M, Sivaramakrishnan.M, Pratebha. B, Vineela KR, Saravanakumar.R
}

\begin{abstract}
The ultimate goal of periodontal therapy is to restore the periodontal health by complete regeneration of the attachment apparatus. Though numerous methods of regeneration are available, researches are directed towards search for autologous materials considering the safety and availability issues. Among the various autologous material options, use of platelet concentrates have found to be more promising due to ease of procurement, handling and biochemical properties. This article throws limelight on the role of platelets on wound healing, preparation, mechanical properties, biochemical properties and clinical application of $\mathrm{PRF}$ in periodontal regeneration.
\end{abstract}

Key Words : periodontal regeneration, platelet rich fibrin, platelet rich plasma, tissue engineering

\section{Introduction}

Periodontitis is an inflammatory disease of bacterial origin, affecting the periodontal tissues, resulting in loss of attachment apparatus. ${ }^{[1]}$ The goal of periodontal therapy is to improve periodontal health and thereby to satisfy the patient's esthetic and functional demands. To achieve this complete reestablishment of the lost attachment is necessary. ${ }^{[2]}$ Histological analysis of periodontal new attachment procedures revealed that periodontal healing occurs with process of repair rather than regeneration. ${ }^{[3]}$

Over the years numerous periodontal regenerative therapies have been developed from simple periodontal debridement to use of various biomaterials like guided tissue regeneration membranes, enamel matrix proteins and bone graft materials. Studies have shown that combination therapies resulted in better results as compared to stand-alone treatment modalities. ${ }^{[4,5]}$ But the availability and cost are other important factors to be considered. Studies have also shown substantial variation in clinical predictability, degree of efficacy, and histological outcomes.
Use of autologous materials is considered a promising alternative. Autologous soft tissue grafts, buccal pad of fat, ${ }^{[6]}$ periosteum, ${ }^{[7]}$ and bone grafts have been tried, but again they were technique sensitive and required a second surgical site. So with the advent of platelet concentrates, the direction of periodontal regenerative therapies took a turn as they were simple to procure and easy to use.

\section{Why Platelet Concentrates?}

Platelet concentrates are blood derived products obtained by centrifugation of autologous blood and are widely used as surgical additive biomaterial to aid tissue healing. ${ }^{[8,9]}$ The intracellular and extracellular events mediated by various signalling proteins during tissue healing are a complex cascade of events that still needs complete understanding. Platelets play a dominant role in every phase of healing of hard and soft tissues. Immediately following tissue injury, platelets are activated and start a sequence of events that result in formation of platelet plug and fibrin clot. This causes hemostasis and secretion of biologically active proteins. ${ }^{[9]}$

* Dr. M. Jananni, Senior lecturer; Dr. B. Pratebha, Professor; Dr.KR.Vineela, Reader; Dr. R. Saravana kumar, Prof. \& Head, Dept of Periodontology; ** Dr. M. Sivaramakrishnan, Senior lecturer, Dept of Oral Pathology \& Microbiology, Indira Gandhi Institute of Dental Sciences, Sri Balaji Vidyapeeth, Puducherry 607 402, India. 
These proteins, initiate tissue healing responses, starting with the initiation, differentiation and chemotaxix of the desired cells, angiogenesis, formation of extracellular matrix and remodelling to the desired tissue. ${ }^{[10]}$ Studies have also found a doseresponse relationship between platelet concentration and the proliferation of human adult mesenchymal stem cells, fibroblasts, and production of collagen by them. ${ }^{[11]}$

Platelets contain numerous growth factors within $\bigotimes$ granules that has a strong influence on the wound healing events. Among them growth factors of periodontal importance are platelet-derived growth factor (PDGF), transforming growth factor (TGF $\bigotimes)$, platelet-derived angiogenesis factor (PDAF), vascular endothelial growth factor (VEGF), plateletderived endothelial growth factor (PDEGF), epidermal growth factor (EGF), insulin-like growth factor (IGF), osteocalcin, osteonectin, fibrinogen, vitronectin, fibronectin, and thrombospondin (TSP). ${ }^{[12]}$ The role of individual growth factors in stages of wound healing is summarized in Table 1.

\section{Classification of Platelet Concentrates}

Dohan et al in 2009 classified platelet concentrates according to the composition of the centrifuged product. Based on this the platelet concentrates were classified into four categories ${ }^{[13]}$

P-PRP - Pure Platelet Rich Plasma

L-PRP - Leucocyte and Platelet Rich Plasma

P-PRF - Pure Platelet Rich Fibrin

L-PRF - Leucocyte and Platelet RichFibrin

\section{Platelet Rich Pasma}

Platelet rich plasma (PRP) is considered as the first generation platelet concentrate preparation. It is obtained by double step centrifugation of autologous blood thereby concentrating platelets in a gel. Hence they are also termed as 'platelet pellet' or 'platelet gel'. ${ }^{[14]}$ But the disadvantages associated with PRP is additional use of calcium chloride and bovine thrombin. The use of bovine thrombin is found to be associated with risk of development of coagulopathies. ${ }^{[15]}$

\section{TABLE 1 - Role of individual growth factors in periodontal regeneration}

\begin{tabular}{|c|l|l|}
\hline S.no & \multicolumn{1}{|c|}{ Growth factor } & \multicolumn{1}{|c|}{ Role in wound healing } \\
\hline 1 & $\begin{array}{l}\text { Transforming growth factor- } \beta \\
\text { TGF- } \beta \text { ) }\end{array}$ & $\begin{array}{l}\text { Stimulates proliferation and chemotaxix of osteoblasts } \\
\text { thereby enhancing the woven bone formation. }\end{array}$ \\
\hline 2 & Platelet-derived growth factor (PDGF & $\begin{array}{l}\text { Stimulates migration and proliferation of mesenchymal } \\
\text { lineage cells }\end{array}$ \\
\hline 3 & $\begin{array}{l}\text { Vascular endothelial growth factor } \\
\text { VEGF) }\end{array}$ & Initiates angiogenesis \\
\hline 5 & Fibroblast growth factor (FGF) & $\begin{array}{l}\text { Enhances fibroblast proliferation, migration and differen- } \\
\text { tiation. }\end{array}$ \\
\hline 6 & Epidermal growth factor (EGF) & $\begin{array}{l}\text { Stimulation of cell proliferation and extracellular matrix } \\
\text { turnover }\end{array}$ \\
\hline
\end{tabular}




\section{Platelet Rich Fibrin}

It is a second generation autologous platelet concentrate biomaterial harvested from a simple blood sample. The main component is a fibrin matrix which incorporates leucocytes, platelets and growth factors in it. PRF was first developed in France in 2000 by Choukroun et al. This protocol proposed by him eliminated the risk associated with use of bovine thrombin. ${ }^{[16]}$

\section{Preparation}

The armamentarium includes, blood collection kit, $10-\mathrm{mL}$ dry glass test tube (without anticoagulant), and a table centrifuge. Blood sample must be collected aseptically from the patient by venipuncture and immediately transferred into the test tube and centrifuged at $3000 \mathrm{rpm}$ or 10 minutes. ${ }^{[17,18]}$ One another protocol suggested to use 2700 rpm for 12 minutes and found similar results. ${ }^{[19]}$

\section{Mechanism}

Absence of anticoagulant triggers platelet activation and fibrin polymerization immediately after it contacts the glass surface. Centrifugation

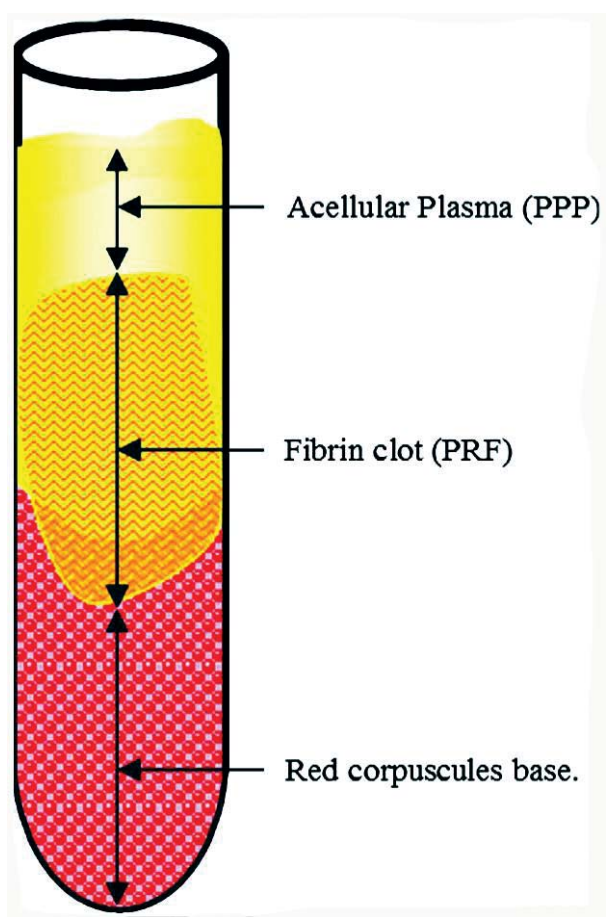

Figure 1 a - Schematic representation of the centrifugation strata. ${ }^{[22]}$

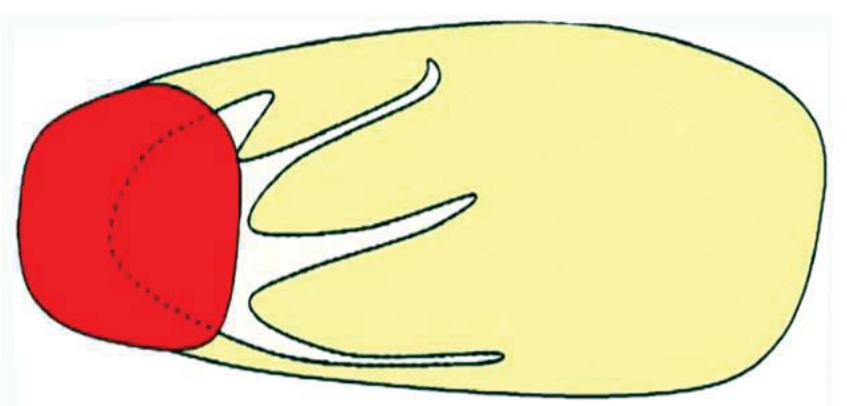

Figure 1 b - The PRF clot (Schematic) ${ }^{[22]}$

splits the components of blood and as a result three layers are formed: the RBC base layer, acellular plasma top layer and a PRF clot in the middle.(Fig 1a,b,c) The PRF clot basically is a strong fibrin mesh with a complex three dimensional structure in which concentrates the platelets and leucocytes. ${ }^{[20]}$

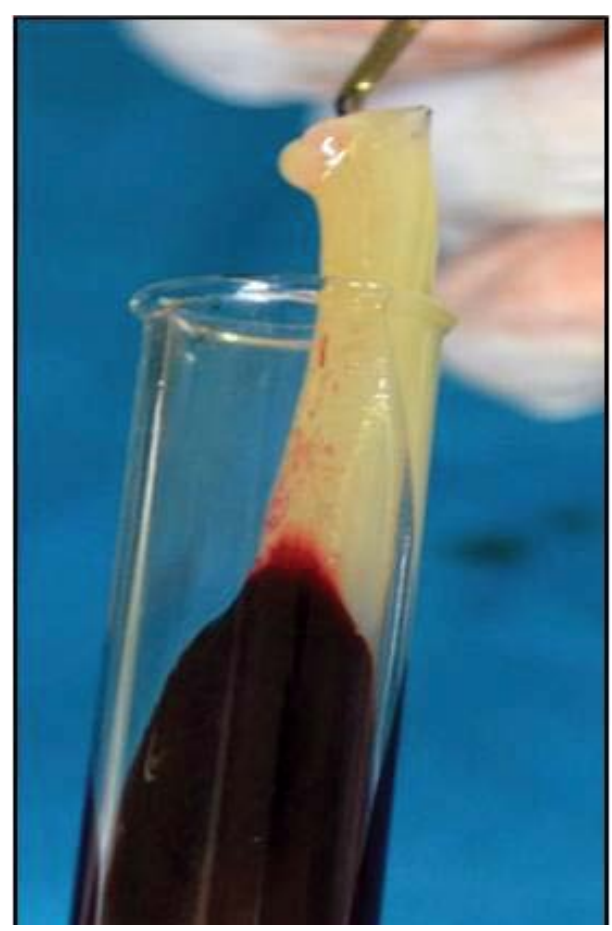

Figure $1 \mathrm{c}-$ PRF clot

The success of this technique entirely depends on the speed of blood collection and transfer to the centrifuge. Quick handling is the only way to obtain a clinically usable PRF clot. Without the anticoagulant, the sample starts to coagulate immediately on contact with the glass. If delay in centrifugation occurs, the fibrin will polymerize in 
a diffuse way and a clot without any firm structure and a small amount of fibrin gel will result.

\section{Material Aspect}

The fact that the polymerization occurs naturally is that main advantage of this material. Since no thrombin is added, the thrombin concentration action on the fibrinogen is almost physiologic. This determines the structure of the fibrin mesh. During the gelling process, the fibrin is assembled in two architecture - condensed tetramolecular or bilateral junctions and connected tri molecular or equilateral junctions. ${ }^{[18]}$ In PRF process the centrifugation results in formation of equilateral junctions, result in weak thrombin concentration that ensures fine, flexible fibrin network. This fine mesh entraps cytokines and allows cell migration. Moreover, this structure will give great elasticity to the fibrin matrix. ${ }^{\text {[19] }}$ (Fig 2) But in PRP, the two step centrifugation

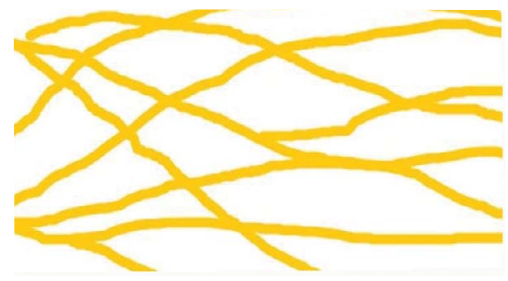

\section{Figure 2-Model of condensed tetra molecular fibrin structure ${ }^{[22]}$}

results in formation of bilateral junctions result in thickened fibrin polymers, which are not favorable for cytokine enmeshment and cellular migration, but

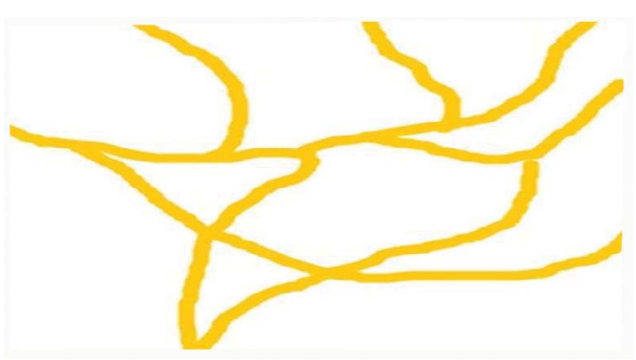

\section{Figure 3 - Model of condensed bilateral fibrin structure ${ }^{[22]}$}

can act as an effective biologic glue to seal tissues due to greater rigidity. $\left(\right.$ Fig 3) ${ }^{[12]}$

\section{Biologic Properties}

Unlike other fibrin adhesives the PRF results from progressive polymerization during centrifugation. Thus it forms a three dimensional organization, coherent than natural clots. As polymerization progresses, the fibrin mesh becomes more intricate and traps the circulating platelets and intrinsic cytokines.(Fig 4)This ensures sustained release and action of cytokines throughout healing and remodeling. PRF promotes the production of phosphorylated extracellular signal-regulated protein kinase (p-ERK) and osteoprotegerin

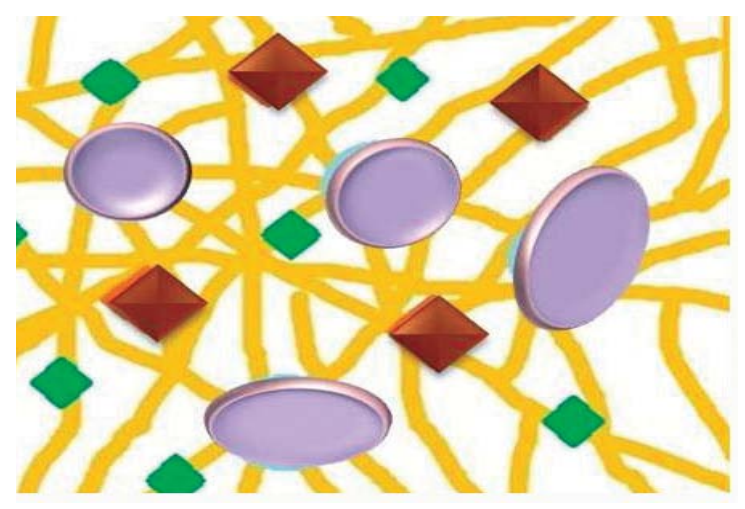

Figure 4 - Platelets and cytokines trapped in fibrin mesh ${ }^{[22]}$

(OPG). This inturn induces proliferation of the osteoblasts. ${ }^{[20]}$ This upregulation of osteoprotegerin and alkaline phosphatise was also found to stimulate the differentiation of cells in human dental pulp. ${ }^{[21,22]}$

\section{Effects on Tissue Healing}

Angiogenesis, immunity and epithelial cover are considered as the key elements of any tissue healing. The PRF and the PRF membrane is found to support all the three phenomena.

\section{Angiogenesis}

The intricate fibrin mesh entraps the platelets which eventually release growth factors that promote angiogenesis like fibroblast growth factorbasic (FGFb), vascular endothelial growth factor (VEGF), angiopointein and platelet-derived growth factor (PDGF). Moreover, the fibrin in the clot regulates 


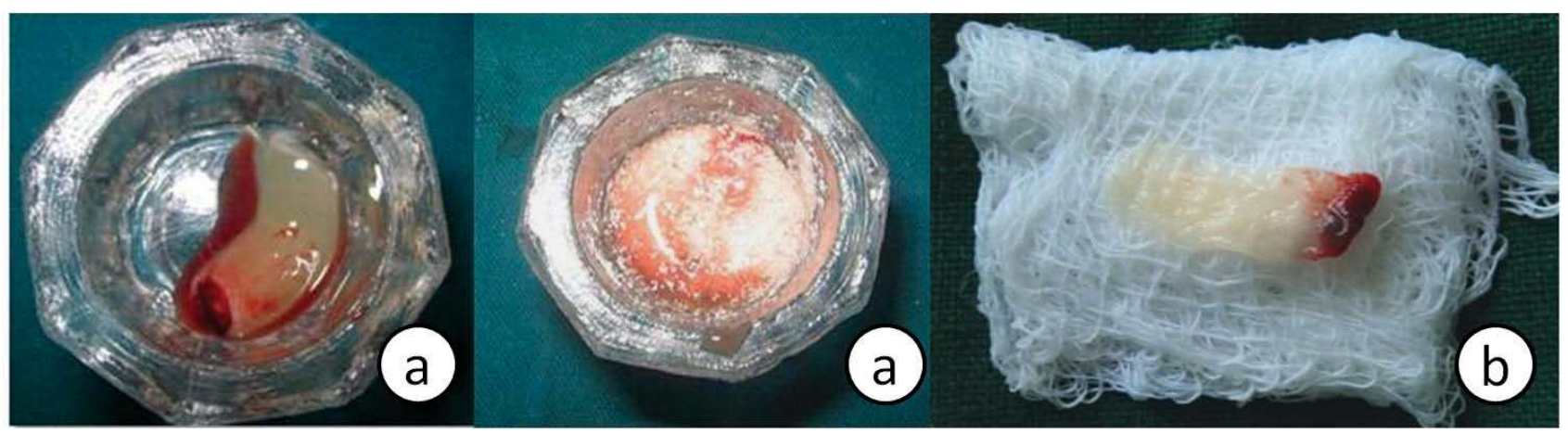

Figure 5 (a) PRF clot mixed with bone graft, (b) - PRF membrane

expression of integrin by endothelium that helps the cells to bind to fibronectin and vitronectin. ${ }^{[22,23,24,25]}$

\section{Immune Modulation:}

Migration of neutrophils and monocytes are regulated by fibronectin the chemical and physical properties of fibrin and by chemotactic agents trapped in its meshes. ${ }^{[26]}$ The fibrin mesh and the entrapped fibrinogen degradation products increase the expression of CD18. This in turn stimulate the migration of neutrophils. ${ }^{[27]} \mathrm{FDP}$ in mesh also modulates phogocytosis and enzymatic degradation of neutrophils ${ }^{28]}$.

\section{Epithelial Cover:}

Growth factors like PDGF,TGF b, and epithelial growth factor, modulate the expression of receptors and integrins that aid in epithelial migration. Fibrin matrix acts as a guide for epithelial migration to cover the injured tissue. ${ }^{[29]}$

\section{PRF And Tissue Engineering}

Tissue engineering triad includes Scaffold, Stem cells and Growth factors. In the past few years, many researches have been conducted to use PRF for tissue engineering.

Gassling et al. ${ }^{[30]}$ in his study concluded that PRF was superior to collagen when used as scaffold in tissue engineering. Moreover, PRF traps the circulating stem cells and also aids in their differentiation due to concentration of growth factors. PDGF acts as chemo attractant for fibroblasts that's aid regeneration. ${ }^{[31,32]}$ In addition its immune functions, like regulation and activation of cytokines like IL-1, IL-4, IL- 6 and TNF- $\beta$ mediates tissue healing and regeneration. ${ }^{[18]}$

\section{PRF in Periodontal Regenration}

The obtained PRF clot can be mixed with the bone graft material and used for regeneration or the clot can be squeezed to form a membrane, which can be adapted over the root or bony surface. (Figure $5 \mathrm{a}, \mathrm{b})$

\section{For root coverage:}

In a randomized controlled trial conducted by Janovich $\mathrm{S}$ et al, 2012 the results showed that PRF and CTG procedures were equally effective in treatment of gingival recessions. ${ }^{[33]} \mathrm{PRF}$ group showed enhanced wound healing and decreased postoperative discomfort. Martinez Zapata et al in his systematic review concluded that use of autologous PRF improved gingival recession. ${ }^{[34]}$

\section{For regeneration in intrabony defects:}

A randomized clinical trial was done bySharma et al. ${ }^{[35]}$ for the treatment of three walled intrabony defects and they found that addition of PRF to the bone graft material resulted in greater bone fill than the controls. In another study by Thoratet al. ${ }^{[36]}$ it was concluded that PRF with bone grafts resulted in more positive results than open flap debridement alone for intrabony defects. Chang et $a 1,{ }^{[37]}$ found better radiographic bone fill following six months of treatment in the sites with bone graft and PRF as compared to bone grafts alone.

\section{PRF in furcation defects:}

Sharma et al studied the effects of PRF in grade II furcation defects and concluded that PRF with bone grafts are a better treatment option as compared to bone grafts alone. ${ }^{[38]}$ 


\section{Disadvantages}

The main disadvantage is the very little amount of material obtained which might be insufficient for periodontal regeneration. Another disadvantage is that it cannot be stored and used at a later point of time since it has to be used immediately after preparation. Storage also results in risk of bacterial contamination of the membrane. Delay in use will result in alteration of the structural and biological properties. Dehydration of the membrane will result in membrane shrinkage, decrease the concentration of growth factor and adversely affect the leukocyte viability. ${ }^{[9]}$

\section{Conclusion}

With these fundamental considerations, PRF is considered as a favorable biomaterial that can protect and glue the wound surface and accelerate tissue healing. Moreover the entrapment of leucocytes and the growth factors promotes true regeneration.

\section{References}

1. Alpiste FM, Buitrago P, de GradoCP, FuenmayorFV, Gil FJ. Periodontal regeneration in clinical practice. Med Oral Patol Oral Cir Bucal 2006;11:e382-92.

2. Zander HA, Polson AH, Heijl LC. Goals of Periodontal Therapy. Journal of Periodontology 1976; 47: 261-66.

3. Listgarten MA, Rosenberg MM. Histological study of repair following new attachment procedures in human periodontal lesions.J Periodontol. 1979; 50:333-44.

4. Chen TH, Tu YK, Yen CC, Lu HK. A systematic review and meta-analysis of guided tissue regeneration/osseous grafting for the treatment of Class II furcation defects. Journal of dental sciences 2013; 8: 209-24.

5. Tu YK, Needleman I, Chambrone L, Lu HK, Faggion CM Jr. A Bayesian network meta-analysis on comparisons of enamel matrix derivatives, guided tissue regeneration and their combination therapies. J ClinPeriodontol. 2012; 39:303-14.

6. Singh J, Prasad K, Lalitha RM, Ranganath K. Buccal pad of fat and its applications in oral and maxillofacial surgery: A review of published literature (February) 2004 to (July) 2009. Oral Surg Oral Med Oral Pathol Oral Radiol Endod. 2010;110:698-705.

7. Soltan M, Smiler D, Soltan C. The inverted periosteal flap: a source of stem cells enhancing bone regeneration. Implant Dent. 2009;18:373-9.

8. Eppley BL, Pietrzak WS, Blanton M. Platelet-rich plasma: a review of biology and applications in plastic surgery. PlastReconstr Surg. 2006;118:147e-159e.

9. Anitua, E, Andia, I, Ardanza, B, et al. Autologous platelets as a source of proteins for healing and tissue regeneration. Thromb. Haemost. 2004;91(4):12-18.

10. Desai CB, Mahindra UR, Kini YK, Bakshi MK. Use of Platelet-Rich Fibrin over Skin Wounds: Modified Secondary
Intention Healing. Journal of Cutaneous and Aesthetic Surgery 2013;6:35-37.

11. Civinini R, Macera A, Nistri L, Redl B, Innocenti M. The use of autologous blood-derived growth factors in bone regeneration. Clinical Cases in Mineral and Bone Metabolism 2011;8:25-31.

12. Khiste SV, Tari RN. Platelet-Rich Fibrin as a Biofuel for Tissue Regeneration. ISRN Biomaterials 2013; 2: 1-6.

13. Dohan E, EhrenfestM, Rasmusson L, Albrektsson T. Classification of platelet concentrates: from pure platelet rich plasma (P-PRP) to leukocyte and platelet - rich fibrin (LPRF).Trends Biotechnical 2009; 27: 158- 67.

14. Marx, R.E. Platelet rich plasma (PRP): What is PRP and what is not PRP? Implant Dentistry 2001;10:225-28.

15. Sanchez AR, Sheridan JP, Kupp LI. Is the platelet rich plasma the perfect enhancement factor? A current review. Int J Oral Maxillofac Implants 2003; 18: 93-103.

16. Sunitha VR, Naidu ME. Platelet rich fibrin: Evolution of a second generation platelet concentrate. Ind J Dent Res 2008; 19: 42-6.

17. Dohan DM, Del Corso M, Charrier JB. Cytotoxicity analyses of Choukroun's platelet-rich fibrin (PRF)on a wide range of human cells: The answer to a commercial controversy. Oral Surg Oral Med Oral Pathol Oral RadiolEndod 2007;103: 587-93.

18. Appel TR, P“otzsch B, M“uller J, von Lindern J, Berg'e SJ, Reich RH. Comparison of three different preparations of platelet concentrates for growth factor enrichment. Clinical Oral Implants Research 2002; 135, 522- 8.

19. Kiran NK, Mukunda KS, Tilakraj TN. Platelet concentrates: a promising innovation in dentistry. Journal of Dental Sciences and Research 2011; 2: 50-61.

20. Dohan, O.M. et al. Ptobelet-ricri fibrin (PRF): a second generation platelet concentrate. Part II: platelet-related biologic features. Oral Surg. Oral Med. Oral Pathol. Oral Radiol. Endod. 2006;101: e45-e50.

21. Dohan DM. Platelet-rich fibrin (PRF): a second generation platelet concentrate. Part 111: leucocyte activation: a new feature for platelet concentrates?. Oral Surg. Oral Med. Oral Pathol. Oral Radiol. Endod. 2006; 101: e5i-e55

22. Dohan, DM, Choukroun J, Diss A, Steve L. Anthony JJ, Mouhyi J, Gogly B. Platelet-rich fibrin (PRF): A secondgeneration platelet concentrate. Part I: Technological concepts and evolution. Oral Surg Oral Med Oral Pathol Oral RadiolEndod 2006; 101: e37-44.

23. Chang IC, Tsai $\mathrm{CH}$, Chang YC. Platelet-rich fibrin modulates the expression of extracellular signal-regulated protein kinase and osteoprotegerin in human osteoblasts. J Biomed Mater Res 2010;13:327-32

24. Huang FM, Yang SF, Zhao JH, Chang YC. Platelet-rich fibrin increases proliferation and differentiation of human dental pulp cells. J Endod 2010;36:1628 - 32.

25. Feng X, Clark RA, Galanakis D, Tonnesen MG. Fibrin and collagen differentially regulate human dermal microvascular endothelial cell integrins: stabilization of alphav/beta3 mRNA by fibrin1. J Invest Dermatol 1999;113:913-19.

26. Sahni A, Odrljin T, Francis CW. Binding of basic fibroblast growth factor to fibrinogen and fibrin.J BiolChem 1998;273: 7554-59.

27. Nehls V, Herrmann R. The configuration of fibrin clots determines capillary morphogenesis and endothelial cell migration. Microvasc Res 1996;51:347-64. 
28. Kazura JW, Wenger JD, Salata RA, Budzynski AZ, Goldsmith GH. Modulation of polymorphonuclear leukocyte microbicidal activity and oxidative metabolism by fibrinogen degradation products D and E. J Clin Invest 1989;83:1916-24.

29. Lanir N, Ciano PS, Van de Water L, McDonagh J, Dvorak AM, Dvorak HF. Macrophage migration in fibrin gel matrices. II. Effects of clotting factor XIII, fibronectin, and glycosaminoglycan content on cell migration. J Immunol 1988;140: 2340-49.

30. Gassling V, Douglas T, Warnke PH, Acxil Y, Wiltfang J, Becker ST.Platelet-rich fibrin membranes as scaffolds for periosteal tissue engineering Clin Oral Implants Res 2010; 21: 543-49.

31. Gray AJ, Bishop JE, Reeves JT, Laurent GJ. A alpha and B beta chains of fibrinogen stimulate proliferation of human fibroblasts. J Cell Sci 1993;104:409-13.

32. Brown LF, Lanir N, McDonagh J, Tognazzi K, Dvorak AM, Dvorak HF. Fibroblast migration in fibrin gel matrices. Am J Pathol 1993;142:273-83.

33. Jankovic S, Aleksic Z, Klokkevold P, Lekovic V, Dimitrijevic B, Kenney EB, et al. Use of platelet-rich fibrin membrane following treatment of gingival recession: A randomized clinical trial. Int $\mathrm{J}$ Periodontics Restorative Dent. 2012;32:e41-50.
34. Martínez-Zapata MJ, Martí-Carvajal A, Solà I, Bolibar I, Angel Expósito J, Rodriguez L, et al. Efficacy and safety of the use of autologous plasma rich in platelets for tissue regeneration: A systematic review.Transfusion. 2009;49:4456.

35. A. Sharma, A.R. Pradeep. Treatment of 3-wall intrabony defects in patients with chronic periodontitis with autologous plateletrich fibrin: a randomized controlled clinical trial. J Periodontol 2011; 82: 1705-12.

36. Thorat M,Pradeep AR, Pallavi B. Clinical effect of autologous platelet-rich fibrin in the treatment of intra-bony defects: a controlled clinical trial. J ClinPeriodontol 2011; 38: 925-32.

37. Chang YC, Wu KC, Zhao JH. Clinical application of platelet-rich fibrin as the sole grafting material in periodontal intrabony defects. Journal of Dental Sciences. 2011; 6: 181 188.

38. Sharma A, Pradeep AR. Autologous platelet-rich fibrin in the treatment of mandibular degree II furcation defects: a randomized clinical trial.J Periodontol. 2011; 82:1396-403. 